\title{
Determination of serum nesfatin-1 level in healthy sheep*
}

\author{
NEŞE HAYAT AKSOY
}

\author{
Department of Biochemistry, Faculty of Veterinary Medicine, Aksaray University, 68100 Aksaray, Turkey
}

\section{Aksoy N. H. \\ Determination of serum nesfatin-1 level in healthy sheep}

Summary

Nesfatin-1 is a peptide hormone first documented in studies with rats. It affects appetite control, hunger, fat storage, obesity, water intake, and body temperature. It also plays a role in the regulation of sleep. The lack of knowledge on the level of nesfatin in sheep prompted this study to estimate serum nesfatin concentrations in healthy sheep of different ages and both sexes. Nesfatin values were found to be significantly lower in females than in males. The following differences were observed between the groups: In the female group, the nesfatin level amounted to $5.23 \pm 1.13 \mathrm{ng} / \mathrm{mL}$ in ewes and $3.14 \pm 0.59 \mathrm{ng} / \mathrm{mL}$ in lambs. In the male group, the nesfatin level was $14.31 \pm 3.94 \mathrm{ng} / \mathrm{mL}$ in adults, but higher in male lambs, at $28.83 \pm 1.72 \mathrm{ng} / \mathrm{mL}$. This preliminary study of serum nesfatin levels in healthy sheep of different ages and both sexes is relevant for future studies and may guide further research on this topic.

Keywords: age differences, sex differences, nesfatin, sheep

Nesfatin (NES), a polypeptide derived from nesfatin-1, calcium, and DNA-binding nucleobindin2 (NUCB2 or NEFA), was first described in rats by Oh-I and colleagues (15). Nesfatin-1 is a neuropeptide regulating hunger and fat storage, acting independently of leptin. It is also a vigorous regulator of metabolism and appetite control. As documented by Oh-I and colleagues, the cell nucleus responsible for appetite control in the hypothalamus secretes nesfatin $(15,20,21)$.

Owing to leptin resistance observed in obese people, metabolic weight control via leptin pathways is impossible. Given that nesfatin interacts strongly with appetite mechanisms, the possible role of NES in the treatment of obesity and related diseases can be considered in cases of leptin-independent decline in food intake (15).

Due to its effects on the prevention of food intake and appetite control (15), NES has been a very popular subject of research in many fields in recent years (20). Researchers have highlighted the significant role of the peptide hormone nesfatin-1 in the energy metabolism of the body and claimed that it may serve as a prognostic factor for obesity, diabetes mellitus, and mental depressive disorders $(6,14,16,18,20,22,27)$. Some studies have revealed that NES also regulates water

* This study was supported by Aksaray University Scientific Research Projects Coordination Unit (Project No: 2015-084). intake and reduces the need for water (26). In addition to the above effects of nesfatin, there are also studies demonstrating its role in body temperature regulation (25) and its effect on sleep patterns (24).

After post-translational modifications, the enzyme prohormone convertase (PC)-1/3 fragments NUCB2 into an N-terminal fragment (NES-1: aa 1-82) and two C-terminal peptides (NES-2: aa 85-163 and NES-3: aa 166-396) $(1-3,19,21)$. Immuno-histochemical studies confirmed the presence of nesfatin-1 and its primary metabolite NUCB2 polypeptides in the central nervous system, hypothalamus, brain-stem, front and mid-brain cell nucleus, and central amygdala cell nucleus $(5,6$, 15, 22, 27). Apart from the central nervous system, the presence of this polypeptide is also evident in peripheral tissues (especially in adipose tissue, gastric mucosa, pancreatic endocrine beta cells, as well as ovarian, uterine, and testicular tissues). After secretion in peripheral tissues, it was able to pass through the blood-brain barrier both ways without molecular saturation, and an intravenous injection remained stable for $20 \min (1,2,5-7,12,15-17,22,23)$.

The primary goal of this research was to confirm the presence of NES peptides in sheep serum. Next, it was aimed at measuring the level of expression of the peptide and at identifying any relationships between the presence of NES peptides in sheep serum and the age 
and sex of the animals. The comparison of the levels of nesfatin- 1 in healthy male and female subjects broken down by age is a fundamental goal of this study.

To date, biochemical, immunohistochemical, physiological, pathological, and pharmacological research on nesfatin has mostly been focused on humans and some animal species (2). In 2006, the presence of nesfatin was demonstrated for the first time in rats' brains (15). Thereafter, the prevalence of this peptide was also investigated in the hypothalamus of pigs (8), mice (10), and dogs (11). This is the first study to investigate serum nesfatin- 1 levels in healthy sheep categorized by age and sex. In literature, in ruminants (cows) just one study reports the nesfatin levels in serum and milk (1). No study has examined the levels of nesfatin that could serve as reference values in healthy sheep. In this context, the present study, investigating the effects of the multifunctional polypeptide nesfatin on the metabolism of healthy sheep, is of utmost importance. Nesfatin, which is likely to be one of the advanced biochemical research, diagnostic and prognostic parameters in the future, may provide academics and clinicians with important clues to biochemical, metabolic, physiological, and endocrinological processes.

\section{Material and methods}

The current research was confirmed by the Bahri Dagdas International Agricultural Research Institute Directorate of Local Ethics Committee of Animal experiments (14.01.2015/35 and 0088).

Sheep blood samples were collected in private enterprises in Aksaray, Turkey. The study population comprised 220 healthy Akkaraman sheep, both females ( $\mathrm{n}=55$ lambs and 55 ewes) and males ( $n=55$ lambs and 55 rams). Regular health controls of these animals are carried out in farms, and they are checked by earring numbers. Blood samples were collected into anticoagulant-free serum tubes and centrifuged for $10 \mathrm{~min}$ at $3000 \mathrm{rpm}$ (4). Fresh samples were used for nesfatin-1 analysis.

Nesfatin assays. Commercially available enzyme-linked immunosorbent assay (ELISA) kits (Sheep Nesfatin ELISA Kit - Shangai Sunred, Biological Tech., China) that detect peptides in biological fluids (serum, plasma, saliva, urine, etc.) were employed to measure the levels of serum peptides blindly.

These kits used an enzyme-linked immune sorbent assay based on the biotin double antibody sandwich technology to assess sheep nesfatin. First, NES was added to wells pre-coated with NES monoclonal antibody and then incubated. Then added anti-NES antibodies labeled with biotin which forms immune complex. After incubation and washing procedures, added substrates. The shades of solution and the concentration of sheep nesfatin are positively correlated. All the samples were measured at $450 \mathrm{~nm}$ in ELISA plate reader (ELx800 Absorbance Microplate Reader-
BioTek, Vermont, USA). Serum nesfatin-1 levels were calculated from standard curves.

Statistical analysis. Data were analyzed with the statistical software SPSS 15.0 for Windows (SPSS Inc., Chicago, IL, USA). The Student t-test was used to analyze differences between the groups. One-way ANOVA was performed to compare group averages in terms of continuous variables. Duncan's multiple comparison test was used to identify different groups after the analysis of variance. The data were represented as means \pm standard error $(\overline{\mathrm{x}} \pm \mathrm{SD})$. Statistical significance was accepted at $\mathrm{p}<0.05$.

\section{Results and discussion}

The results of this study show much higher nesfatin levels in both groups of males compared with females (Tab. 1). Significantly higher NES values were detected in males than in females $(p<0.05)$ (Fig. 1). Considering all four groups (differentiated by age and sex), nesfatin values were significantly lower in females than they were in males, but differences were also observed within groups. The differences observed within the groups are as follows:

In the female group, the nesfatin level was 5.23 $\pm 1.13 \mathrm{ng} / \mathrm{mL}$ in adults and $3.14 \pm 0.59 \mathrm{ng} / \mathrm{mL}$ in lambs, but this difference was not statistically significant $(\mathrm{p}>0.05)$.

In the male group, the nesfatin level was 14.31 $\pm 3.94 \mathrm{ng} / \mathrm{mL}$ in adults, whereas the value measured in lambs was significantly higher at $28.83 \pm 1.72 \mathrm{ng} /$ $\mathrm{mL}(\mathrm{p}<0.05)$.

Thus, as far as age is concerned, the nesfatin level was higher in female ewes than in female lambs. In the male group, on the other hand, it was lower in adults (rams) than in lambs. The nesfatin level in ewes was 1.66 times as high as it was in female lambs (Fig. 1), whereas the NES level in male lambs was 2.04 times as high as in rams (Fig. 1). Furthermore, the results show that serum nesfatin levels were notably higher in
Tab. 1. Levels of serum nesfatin in Akkaraman sheep $(\bar{x} \pm$ SD)

\begin{tabular}{|l|c|c|c|c|}
\hline Polypeptide (Unit) & Ewes & Female lambs & Rams & Male lambs \\
\hline Nesfatin (ng/mL) & $5.23 \pm 1.13^{\mathrm{a}}$ & $3.14 \pm 0.59^{\mathrm{a}}$ & $14.31 \pm 3.94^{\mathrm{ab}}$ & $28.83 \pm 1.72^{\mathrm{ab}}$ \\
Significance & \multicolumn{2}{|c|}{$(\mathrm{p}>0.05)$} & $(\mathrm{p}<0.05)$ \\
\hline
\end{tabular}

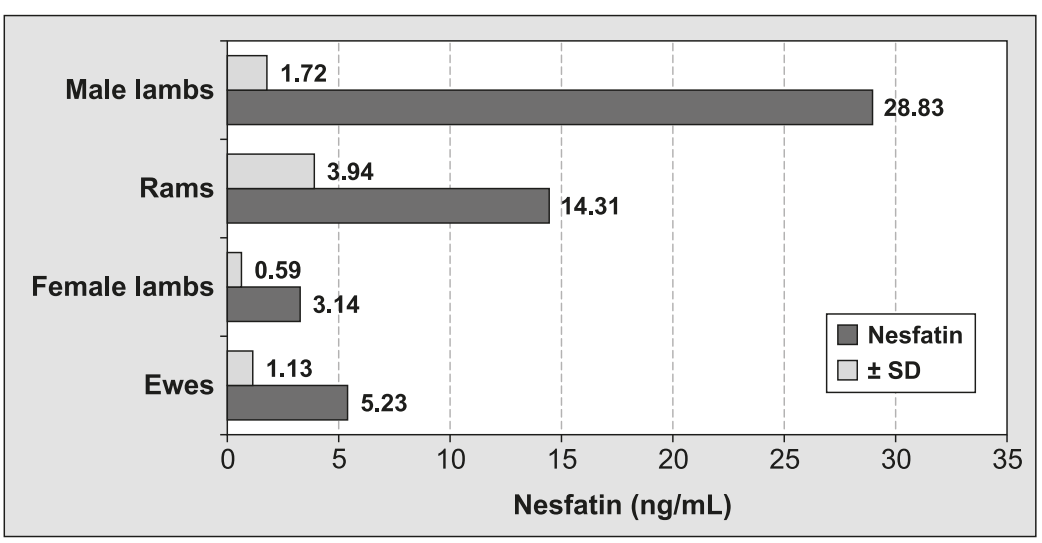

Fig. 1. Levels of serum nesfatin-1 in four groups of sheep 
males than then they were in females, and this difference was observed both between ewes and rams and between female and male lambs (Fig. 1).

A positive relation was confirmed between the NES level and age difference (young-adult), especially in males. Higher levels of nesfatin were observed in males than in females (Fig. 1). Female adults (ewes) showed higher nesfatin levels than female lambs (Fig. 1). Unlike in females, nesfatin levels in adult males (rams) were lower than they were in male lambs $(p<0.05)$ (Fig. 1).

The published literature includes no report that confirms the presence of nesfatin-1 in the blood of healthy sheep. This study provides preliminary data on nesfatin-1 levels in sheep of different ages and both sexes. Elucidating the function and metabolism of nesfatin-1 in sheep is an important topic for further research. At present, no comparative interpretations can be drawn from this point, because of the lack of studies on nesfatin in healthy sheep (Akkaraman sheep).

The increase in nesfatin in female adults may be due to hormonal differences. Alternatively, lower nesfatin levels in male adults than in male lambs may be due to age-related differences. Perhaps, while estrogen, whose synthesis increases at maturity, has a positive effect on nesfatin levels in females, testosterone may have a negative effect in males. Since there is no literature to compare this distinction, interpretations are limited. Hormonal interactions may be responsible for these differences between adults and lambs and between males and females, which can be elucidated by subsequent studies.

Bergmann et al. (3) investigated the role of serum nesfatin-1/NUCB2 level as a biomarker of impaired glucose metabolism in human subjects without diabetes. They reported significantly lower nesfatin-1/ NUCB2 levels in men than in women. This report (3) is in contradiction with the results obtained from the sheep in the current study and is open to interpretation. As stated in their article, it is strongly believed that these seemingly dissimilar (or even contradictory) results may be attributed to racial, species, and even individual genetic differences. It is an important possibility that gender and age differences have a significant effect on nesfatin-1 concentrations and endocrine activity through the effects of sex hormones.

Further studies with different animal species and breeds by considering endocrine and metabolic activities will be able to explain the differences in nesfatin levels depending on age and gender. Probably, the hormonal and physiological characteristics of animals may be responsible for the higher concentration of nesfatin detected in ewes compared with female lambs. On the other hand, physiological, hormonal, and mostly biochemical metabolic variations may contribute to the lower levels of NES in rams compared with male lambs.
Owing to its effect on the hypothalamus, NES, secreted from the cell nucleus responsible for appetite control, which inhibits food intake and controls appetite (20), has been a topic of intensive research over the last ten years. This multifunctional polypeptide, which is still under investigation, has been relevant in exploring the functions of metabolism, particularly with regard to biochemical and hematological parameters in healthy animals.

Nesfatin-1 levels were estimated in plasma, milk, cheese, and cheese whey in a study conducted with dairy cows (1). That study confirmed the presence of nesfatin- 1 in milk and milk products, and also reported the plasma nesfatin level to be $4.02 \pm 1.51 \mathrm{ng} / \mathrm{mL}$. Comparing cattle ruminants (dairy cows) and small ruminants (ewes), we find that the serum nesfatin level in cows was fairly close to $5.23 \pm 1.13 \mathrm{ng} / \mathrm{mL}$ obtained in the present study for ewes.

According to the literature, the initiation of puberty and fertility are precisely correlated with the amount of metabolic energy reserves in the body, which is regulated by the primary factors that control appetite. It is suggested that nesfatin-1, as an appetite-inhibiting hormone, has a marked impact on reproduction metabolism (9). This means that nesfatin levels may be higher during growth, development and active reproductive physiological periods.

To restore metabolism homeostasis impaired due to growth, development, and mass increase in young male sheep, nesfatin-1 synthesis may have increased as a compensatory mechanism. On the other hand, this may explain why NES levels in the adult mother sheep, especially in the lactating ones, were higher than they were in the female lambs.

Both central and environmental signals and physiological needs regulate food intake, one of the most basic needs and instincts in all animals, including humans. Nesfatin levels may also be increased during the physiological periods of reproduction (ewes, rams), growth and development (lambs), rapid metabolic activities (male lambs in particular), and in cold climate (all groups), and these conditions may also have influenced the sheep in the present study.

Nesfatin-1 has a significant impact on food intake and body temperature. Cold-induced nesfatin-1 expression may enable nuclei in different parts of the brain to adapt to a lower temperature (13). In this study, blood was collected from sheep in May. Therefore, the climatic conditions of that month may have affected nesfatin levels, which regulate body temperature.

According to research performed since 2006 (15), patients' response to treatment reflected a probable beneficial effect of nesfatin-1 polypeptides on the management of related metabolic diseases (2). Nesfatin polypeptide, as a new biochemical parameter in clinical practice and an important addition to advanced biochemical data, can be assessed in diseases and 
compared with its normal values in the blood (serum or plasma) of various animals.

This parameter, which is most likely to be among the basic biochemical diagnostic variables in the future, will provide academics and clinicians with important clues to both physiological and endocrinological processes. The field of veterinary surveillance provides important insights on the diagnosis, early diagnosis, etiology, and pathogenesis of the (nesfatin related) possible metabolic diseases, detection as well as the usefulness of treatment methods applied. At this point, apart from the basic biochemical parameters of breeds, the determination and use of advanced biochemical values will be the most beneficial approach.

This preliminary study will be effective in guiding future research on this topic.

\section{References}

1. Aydin S.: Multi-functional peptide hormone NUCB2/nesfatin-1, Endocrine 2013, 44, 312-325

2. Aydin S.: Presence of adropin, nesfatin-1, apelin-12, ghrelins and salusins peptides in the milk, cheese whey and plasma of dairy cows. Peptides 2013, $43,83-87$.

3. Bergmann K., Kretowicz M., Manitius J., Sypniewska G.: Gender differences in association of serum nesfatin-1 with selected metabolic risk factors in normoglycemic subjects: A preliminary study. J. Diabetes 2015, 7, 433-434.

4. Coles E. H.: Veterinary Clinical Pathology $4^{\text {th }}$ Ed.: W. B. Saunders Co. Philadelphia 1986.

5. Cowley M. A., Grove K. L.: To be or NUCB2, is nesfatin the answer? Cell Metab. 2006, 4, 421-422.

6. Dore R., Levata L., Lehnert H., Schulz C.: Nesfatin-1: functions and physiology of a novel regulatory peptide. Journal of Endocrinology 2017, 232, 45-65.

7.Finelli C., Martelli G., Rossano R., Padula M. C., Sala N., Sommella L., Tarantino $G$.: Nesfatin-1: role as possible new anti-obesity treatment. Excli Journal 2014, 13, 586-591.

8. Gaigé S., Bonnet M. S., Tardivel C., Pinton P., Trouslard J., Jean A. Guzylack L., Troadec J. D., Dallaporta M.: C-FOS immunoreactivity in the pig brain following deoxynivalenol intoxication: focus on NUCB2/nesfatin-1 expressing neurons. Neurotoxicology 2012, 34, 135-149.

9. García-Galiano D., Navarro V. M., Roa J., Ruiz-Pino F., Sánchez-Garrido M. A., Pineda R., Castellano J. M., Romero M., Aguilar E., Gaytán F., Diéguez C., Pinilla L., Tena-Sempere M.: The anorexigenic neuropeptide, nesfatin-1, is indispensable for normal puberty onset in the female rat. J. Neurosci. 2010, 30, 7783-7792.

10. Girardet C., Bonnet M. S., Jdir R., Sadoud M., Thirion S., Tardivel C., Roux J., Lebrun B., Wanaverbecq N., Mounien L., Trouslard J., Jean A., Dallaporta M., Troadec J. D.: The food-contaminant deoxynivalenol modifies eating by targeting anorexigenic neurocircuitry. PLoS ONE. 2011, 6, 10, e26134, doi: 10.1371/journal.pone.0026134.

11. Gonkowski S., Rychlik A., Nowicki M., Nieradka R., Bulc M., Całka J.: Population of nesfatin 1-like immunoreactive (LI) cells in the mucosal layer of the canine digestive tract. Res. Vet. Sci. 2012, 93, 1119-1121.

12. Kim J., Yang H.: Nesfatin-1 as a New Potent Regulator in Reproductive System. Dev. Reprod. 2012, 16, 253-264.

13. Könczöl K., Pintér O., Ferenczi S., Varga J., Kovács K., Palkovits M., Zelena D., Tóth Z. E.: Nesfatin-1 exerts long-term effect on food intake and body temperature. Int. J. Obes. (Lond). 2012, 36, 1514-1521, doi: 10.1038/ ijo.2012.2.

14. Masuo K.: Nesfatin-1 could be a strong candidate obesity or diabetes medication, if blood pressure elevation can be controlled. Hypertens Res. 2014, 37 98-99.

15. Oh-I S., Shimizu H., Satoh T., Okada S., Adachi S., Inoue K., Eguchi H., Yamamoto M., Imaki T., Hashimoto K., Tsuchiya T., Monden T., Horiguchi K. Yamada M., Mori M.: Identification of nesfatin-1 as a satiety molecule in the hypothalamus. Nature 2006, 443, 709-712.

16. Pan W., Hsuchou H., Kastin A. J.: Nesfatin-1 crosses the blood-brain barrier without saturation. Peptides 2007, 28, 2223-2228.

17. Price T. O., Samson W. K., Niehoff M. L., Banks W. A.: Permeability of the blood-brain barrier to a novel satiety molecule nesfatin-1. Peptides 2007, 28 , 2372-2381.
18. Prinz P., Stengel A.: Nesfatin-1: current status as a peripheral hormone and future prospects. Current Opinion in Pharmacology 2016, 31, 19-24.

19. Shimizu H., Oh-I S., Okada S., Mori M.: Nesfatin-1: an overview and future clinical application. Endocr. J. 2009, 56, 537-543.

20. Stengel A.: Nesfatin-1 - More than a food intake regulatory peptide. Peptides 2015, 72, 175-183.

21. Stengel A., Goebel M., Wang L., Rivier J., Kobelt P., Mönnikes H., Lambrecht $N$. W., Taché Y.: Central nesfatin-1 reduces dark phase food intake and gastric emptying in rats: differential role of corticotropin-releasing factor2 receptor. Endocrinology 2009, 150, 4911-4919.

22. Stengel A., Taché Y.: Nesfatin-1-role as possible new potent regulator of food intake. Regul. Pept. 2010, 163, 18-23.

23. Su Y., Zhang J., Tang Y., Bi F., Liu J. N.: The novel function of nesfatin-1: antihyperglycemia, Biochem. Biophys. Res. Commun. 2015, X391, 1039-1042.

24. Vas S., Adori C., Konczol K., Katai Z., Pap D., Papp R. S., et al.: Nesfatin-1/ NUCB2 as a potential new element of sleep regulation in rats. PLoS ONE 2013, 8, e59809.

25. Wernecke K., Lamprecht I., Johren O., Lehnert H., Schulz C.: Nesfatin-1 increases energy expenditure and reduces food intake in rats. Obesity (Silver Spring) 2014, 22, 1662-1668.

26. Yosten G. L., Redlinger L., Samson W. K.: Evidence for a role of endogenous nesfatin-1 in the control of water drinking. J. Neuroendocrinol. 2012, 24, 1078-1084.

27. Zhai T., Li S. Z., Fan X. T., Tian Z., Lu X. Q., Dong J.: Circulating Nesfatin-1 Levels and Type 2 Diabetes: A Systematic Review and Meta-Analysis. J. Diabetes Res. 2017, 2017 (10):1-8, doi: 10.1155/2017/7687098.

Corresponding author: Neșe Hayat Aksoy, Asst. Prof. Dr., Department of Biochemistry, Faculty of Veterinary Medicine, Aksaray University, 68100 Aksaray, Turkey 